\title{
Reliability of hand fellows' measurements and classifications from radiographs of distal radius fractures
}

\author{
Joy C MacDermid PhD ${ }^{1}$, Robert S Richards MD FRCS ${ }^{1}$, Allan Donner PhD ${ }^{2}$, Nick Bellamy MD MSc${ }^{2}$, \\ James H Roth MD ${ }^{1}$, Kevin A Hildebrand MD FRCS ${ }^{3}$ \\ ${ }^{1}$ Hand and Upper Limb Centre, Clinical Research Laboratory, St Joseph's Health Centre, ${ }^{2}$ Department \\ of Epidemiology and Biostatistics, University of Western Ontario, London, Ontario, and Department of \\ Orthopaedic Surgery, University of Calgary, Calgary, Alberta
}

\section{JC MacDermid, RS Richards, A Donner, N Bellamy, JH Roth, KA Hildebrand. Reliability of hand fellows' measurements and classifications from radiographs of distal radius fractures. Can J Plast Surg 2001;9(2):51-58.}

The inter-rater reliability of classification systems and the direct measurement of fracture displacement was evaluated for two hand fellows in 128 radiographs of distal radius fractures. The fracture classifications rated were the Older, Mayo, AO, McMurtry, Universal and Frykman systems. Measurements of displacement were radial tilt, radial shortening and dorsal angulation on pre- and postreduction films. Intraclass correlation coefficients (ICCs) and kappas, and their associated 95\% confidence intervals were calculated. Inter-rater reliability for classification systems was poor, with the exception of the Older system (kappa $=0.73$ ). Prereduction measurement of radial inclination, dorsal angulation and radial shortening had excellent reliability (ICC 0.77). Postreduction films exhibited lower reliability in the same measurements (ICC 0.76). Hand fellows reported inconsistent use of classification systems or radiographical measurements in clinical practice. Further training and/or an increased emphasis on direct measurements, rather than classifications, may be warranted.

Key Words: Classification; Distal radius; Fracture; Radiographs; Reliability; Wrist

\section{Radiographies de fracture du radius distal : fiabilité des mesures et des systèmes de classification}

RÉSUMÉ : Le coefficient d'objectivité des systèmes de classification et des mesures directes de déplacement a été évalué entre deux spécialistes des mains à partir de 128 radiographies de fracture du radius distal. Ca derniers ont appliqué différents systèmes de classification des fractures : l'Older, le Mayo, l'AO, le McMurtry, l'Universal et le Frykman. Les mesures de déplacement tenaient compte de l'inclinaison et de l'accourcissement du radius ainsi que de la déviation dorsale avant et après la réduction. On a calculé le coefficient de corrélation interclasse (CCI) et les valeurs Kappa correspondantes, ainsi que les intervalles de confiance à $95 \%$ qui les étaient associés. Le coefficient d'objectivité des systèmes de classification était médiocre, à l'exception du système Older (Kappa : -0,73). La fiabilité des mesures de l'inclinaison et de l'accourcissement du radius ainsi que de la déviation dorsale avant la réduction était excellente (CCI 0,77). Par contre, la fiabilité de ces mêmes mesures après la réduction était moindre (CCI 0,76 ). Les deux évaluateurs ont fait état, en pratique clinique, d'un usage inconsistant des systèmes de classification ou des mesures prises sur les radiographies. Il pourrait être justifié de donner une formation plus poussée sur les mesures directes ou d'en préconiser la prise plutôt que d'avoir recours aux systèmes de classification.

$I_{n}^{\mathrm{d}}$ deally, a radiographical fracture classification or measurement should be a standardized measure that permits clinicians to describe a fracture for effective communication with others, suggest a treatment plan and assist with predicting the results of treatment. Standardization of measurement requires that radiographical indicators have documented reli-

Correspondence and reprints: Dr Joy C MacDermid, Hand and Upper Limb Centre, Clinical Research Laboratory, St Joseph's Health Centre, PO Box 5777, London, Ontario N6A 4L6. Telephone 519-646-6100 ext 64636, fax 519-646-6049, e-mail jmacderm@julian.uwo.ca 
ability, validity and normative values. Reliability, or consistency in measurement, underlies the validity of classification systems, their ability to predict treatment requirements or outcomes, and the value of published normative values. The importance of reliable radiographical measures in scientific reporting has been recognized. For example, The Journal of Orthopaedic Trauma requires that any work submitted by prospective authors use radiographical classifications with a documented reliability of a kappa of at least 0.55 (1).

A variety of anatomical deformities may contribute to classification systems for distal radius fractures (DRF). The presence of articular involvement, the amount of comminution, the degree of displacement in various planes and fracture stability are a few of the major concepts involved in fracture management and, thus, are represented in certain classification systems. Neither the reliability nor the relative importance of specific anatomical deformities occurring with DRF has been well defined. Thus, a variety of classification systems continue to be used in clinical literature.

Whereas fracture classification systems categorize anatomical disruption due to fracture into a limited number of categories, these disruptions can also be directly measured on the radiograph. Angles or distances measured from a radiograph are on a continuous scale. The problem with a limited number of response options that occurs with ordinal scales is no longer an issue. However, radiographical measures are limited in their ability to describe the three-dimensional nature of the injury. Thus, radiographical classifications remain popular in clinical communication.

A number of publications have addressed the reliability of radiographical measures and classification systems. Reliability has been examined for the ankle (2-4), acromial morphology (5), hip arthroplasty interface evaluation (6) and wrist fracture (7). Moderate to poor agreement has been documented for the Gustilo and Anderson classification system for open fractures (8), the Neer classification system for proximal humerus fractures (9-11), the AO classification system (12) and the Garden classification system for femoral neck fractures (13).

Swiontkowski et al (14) observed that the reported reliability for most classification systems is in the moderate range and attributed this to forcing continuous variables into dichotomous categories. Radiographical quality is not thought to be the primary source of disagreements (15). Despite questions regarding the reliability of classification systems, the use of the AO/OTA system has been recommended by the primary organization for musculoskeletal injury in the world, and mechanisms for change have been established (14). However, recognizing that increasing the number of levels of classification systems tends to reduce reliability, it has been suggested that authors limit themselves to communicating at the broadest level, for example, the 'type' of fracture.

The AO classification system was evaluated for inter-rater reliability by 36 professionals with a variety of experience levels (7). The AO classification system types are extra- articular, partial articular and complete articular. Groups and subgroups provide finer gradations. Among the raters, there were eight attending surgeons, nine fellows, 15 residents and four nonclinicians. Illustrating the lack of 'standard practice', only three of 36 raters regularly used the AO system. Fifteen raters used the Frykman scale, six used the Universal scale and 12 did not use any scale regularly, although $81 \%$ of the clinicians were familiar with the AO system. A 30 min review of the AO system was used to train raters before data collection. When looking at the three fracture types rated by attending surgeons, an unweighted kappa of 0.68 was observed. With finer gradations the kappas fell to 0.48 for groups and 0.33 for the subgroups. Kappas obtained for fellows and attending surgeons were similar, with residents' kappas being lower and nonclinicians obtaining the least reliable scores. Kreder et al (7) also noted that the AO system addressed joint involvement but not displacement, and suggested that displaced and nondisplaced descriptors be added to the system.

Andersen et al (16) studied the reliability of four different classification systems, when two attending hand surgeons and two radiologists evaluated 55 sets of DRF radiographs. Intra- and inter-rater reliability were fair to moderate. Only when the AO system was reduced to the three types (A, B and C) of fractures was substantial agreement achieved. These authors suggested that it is inappropriate to compare results between studies or guide treatment on the basis of classification, given the poor observed reliability in experienced clinicians and radiologists (16).

Authors have consistently shown that disagreements occur at each successive level of tiered systems and, thus, agreement can be poor when one extends classification past broad categories. The relatively unimpressive reliability reported in the majority of radiographical classification studies may reflect the difficulty in taking data that are continuous and translating them into mutually exclusive categories. For example, there may be disagreements on whether a fracture is intra-articular, which may occur more frequently when the fracture line is close to the joint surface; involvement on the ulnar surface when it is minimally involved; and step-off, where the step is minimal. When the data have been categorized, small differences between these measures become equivalent to large measurement errors.

An alternative method of expressing radiographical findings is through direct measurements; therefore, the reliability of these methods is equally important. Measures of dorsal angulation, radial inclination and radial shortening are commonly reported in the literature. Bilic et al (17) pointed out that there is a possibility of incorrect determination of radial shortening when measuring according to the palmar or dorsal edge of the ulnar notch when a marked change in palmar tilt occurs. This is because the edge of the ulnar notch rotates in a dorsal direction and often migrates in a distal direction such that bone loss is not apparent. Some authors use radial shortening without stating whether the palmar or dorsal edge of the ulnar notch was used as a landmark, despite the fact that these two methods give different results (17). Furthermore, it 

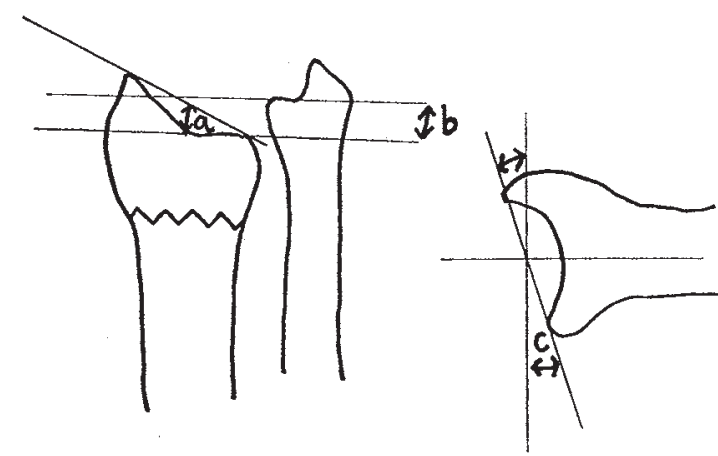

Figure 1) Analysis of radial shortening and dorsal angulation. a Radial tilt; $b$ Radial shortening (loss of radioulnar length); c Dorsal angulation (loss of palmar tilt due to fracture)

is common clinical practice for physicians to eyeball radiographical deformities rather than to directly measure and document parameters such as dorsal angulation and radial shortening.

Kreder et al (18) conducted a study to define the limits of error of radiographical measures used to assess distal radius fractures in a multicentre trial. After meeting to discuss standardization of technique, study raters modified methods from those described in the literature to make the instructions more specific. They used six films from healed fractures because their raters reported fatigue and loss of concentration after this number of films. Step, gap, radial angle, radial length, radial shift, ulnar variance, palmar tilt and dorsal shift were measured according to standardized instructions. Raters used high quality protractors, rulers and fine-tipped markers to draw lines and angles. Repeat measurements were taken by the same raters two to four weeks later. Substantial inter-rater consistency was observed for ulnar variance (intraclass correlation coefficient $[\mathrm{ICC}]=0.82$ ), palmar tilt $(\mathrm{ICC}=0.74)$, radial shift $(\mathrm{ICC}=0.67)$ and radial length ( $\mathrm{ICC}=0.44$ over all raters, but ICC $=0.89$ in attending physicians). Lower reliability in radial length measures was attributed to differences in landmarking. For example, study participants used the distal ulnar articular surface, while others used the distal medial radial articular surface. Some radiographical measures showed poor to fair reliability (ie, dorsal shift [ICC $=0.42]$, and radial angle and step deformity [ICC 0.27 to 0.38$]$ ). Higher agreement was achieved for intrarater agreement among senior raters, although consistency between fellows and attending surgeons who reportedly routinely used these measures was no higher than that of raters who did not routinely use them. Intrarater reliability was similar to inter-rater reliability (ie, high for ulnar variance $[\mathrm{ICC}=0.85]$ and low for gap and step deformity $[\mathrm{ICC}=0.22])$. The tolerance limits for error were as follows: palmar tilt 15 , ulnar variance $4 \mathrm{~mm}$, radial shift $5 \mathrm{~mm}$, radial length $10 \mathrm{~mm}$, dorsal shift $8 \mathrm{~mm}$, gap $3 \mathrm{~mm}$ and step $3 \mathrm{~mm}$. It may be that acute radiographs are more reliably measured than healed fractures because fracture lines have not yet been obscured by the healing process (18).

It has been suggested that kappa values of at least 0.55 should be demonstrated before any classification scale is used to describe clinical results in peer-reviewed literature (1). According to Fleiss (19) a kappa of greater than 0.75 is excellent. Others suggest that a kappa greater than 0.60 is substantial and a kappa greater than 0.80 is almost perfect (20). Regardless of the benchmark, journals are becoming increasingly reluctant to publish clinical results stratified on the basis of classification systems that have not been substantiated $(1,21)$.

Fracture classifications are popular, partially because 'names' for various fracture patterns can simplify communication. Fracture classifications have been problematic in terms of reliability and universal acceptance; consequently, the ability of these classification scales to serve as communication tools has been restricted. Furthermore, the other purposes of describing an injury, for example, to guide treatment and aid in prognostication, may be less well served by classifications than by direct measurements. For these reasons, we were motivated to evaluate fracture classification systems and measurements in radiographical assessments of DRF to determine the relative inter-rater reliability. A secondary purpose of the present study was to evaluate the effect on rater reliability of using a volar (compared with dorsal) surface to assess radial length.

\section{MATERIALS AND METHODS}

A total of 128 radiographs of DRF (64 prereduction and postreduction films) were rated by two hand surgery fellows. The hand surgery fellows were in their last year of training and had used radiographical classifications. One rater consistently used the McMurtry system and the other rater had not consistently used any one system. Both reported that, although they had performed the radiographical measures previously, the actual measurements were not routinely measured or recorded by themselves, the consultant or the radiologist. The observers reviewed the classification systems together and kept a description of the systems with them during review of radiographs. Supplemental training or discussion of results during the study was not permitted.

\section{Radiographical measures}

Measurements of radial shortening from the distal ulnar to distal radial surfaces were taken as described by Warwick et al (22). A measurement of radial shortening by using the volar surface was also performed to determine the effect of using the volar surface as a landmark in termination of radial shortening. Dorsal angulation was measured from lateral radiographs as the angle formed by the line perpendicular to the long axis and the articular surface indicated by a line joining the volar and dorsal margins of the radial surface (23) (Figure 1).

\section{Fracture classifications}

Fractures were classified according to the following classification systems: AO (24), Universal (25), Mayo (26,27), McMurtry (28), Older (29) and Frykman (30). The fracture classification scales are listed in Appendix 1. 
TABLE 1

Characteristics of subjects with distal radius fractures

\begin{tabular}{|c|c|c|}
\hline Characteristics & \multicolumn{2}{|c|}{ Mean \pm SD } \\
\hline Number of patients & \multicolumn{2}{|r|}{67} \\
\hline Age (years) & \multicolumn{2}{|r|}{5416} \\
\hline Grip at one year & \multicolumn{2}{|c|}{$89 \%$ of unaffected side } \\
\hline $\begin{array}{l}\text { Active range of motion } \\
\text { at one year } \\
\text { (six motions) }\end{array}$ & \multicolumn{2}{|c|}{$88 \%$ of unaffected side } \\
\hline Jebson's Checkers subtest & \multicolumn{2}{|c|}{$93 \%$ of unaffected side } \\
\hline Tester \#1 measures & Prereduction \pm SD & Postreduction \pm SD \\
\hline Radial inclination & 16.5 & 20.4 \\
\hline Dorsal angulation & 14.3 & -3.36 .0 \\
\hline $\begin{array}{l}\text { Radial shortening } \\
\quad \text { (dorsal landmark) }\end{array}$ & 1.33 .1 & $-0.84 \quad 1.9$ \\
\hline $\begin{array}{l}\text { Radial shortening } \\
\quad \text { (volar landmark) }\end{array}$ & $-2.3 \quad 2.5$ & $-2.1 \quad 2.4$ \\
\hline Tester \#2 measures & Prereduction \pm SD & Postreduction \pm SD \\
\hline Radial inclination & 16.57 .7 & 20.15 .2 \\
\hline Dorsal angulation & 14.119 .5 & -0.098 .8 \\
\hline $\begin{array}{l}\text { Radial shortening } \\
\quad \text { (dorsal landmark) }\end{array}$ & 0.343 .5 & -1.362 .4 \\
\hline $\begin{array}{l}\text { Radial shortening } \\
\quad \text { (volar landmark) }\end{array}$ & $\begin{array}{ll}-1.8 & 2.5\end{array}$ & $\begin{array}{lll}-1.36 & 2.3\end{array}$ \\
\hline
\end{tabular}

\section{Data analysis}

ICCs are commonly used to quantify rater reliability in cardinal data, as in true numerical data, such as angles and length of displacement (31). Kappa is most commonly used to evaluate reliability of nominal (nonordered) or ordinal (ordered) data with a limited number of categories such as fracture classification systems. Debate exists over the appropriate statistic to be used for ordinal data, especially as the number of categories increases. It has been documented that kappa and ICC are equivalent when the marginals are equal (32). Because both cardinal and ordinal data were used and because the current benchmark for classification systems has been described as a minimum kappa, both statistics were calculated. A weighted kappa was calculated for classification scales (33). Quadratic weighting was selected because this weighting has been described as giving results equivalent to the ICC (32). The ICC type $(1,2)$ was chosen as the statistic of choice because two randomly selected raters rated all films fitting the model described by Shrout and Fleiss (31). The 95\% confidence intervals were calculated for all ICCs as described by Shrout and Fleiss (31). A reliability statistic of less than 0.40 was considered to be poor, 0.40 to 0.75 was considered to be moderate and greater than 0.75 was considered to be excellent (19), whereas a kappa greater than 0.55 was considered to be acceptable.
TABLE 2

Inter-rater reliability of radiographical measures in distal radius fractures $(n=67)$. Intraclass correlations $(95 \%$ confidence interval $[\mathrm{CI}])$

\begin{tabular}{lcc}
\hline Measure & Initial $\mathbf{( 9 5 \%} \mathbf{~ C I})$ & Postreduction $\mathbf{( 9 5 \% ~ C I )}$ \\
\hline Radial inclination & 0.99 & 0.76 \\
& $(0.98-0.99)$ & $(0.65-0.83)$ \\
Dorsal angulation & 0.92 & 0.59 \\
& $(0.88-0.95)$ & $(0.41-0.72)$ \\
Radial shortening & 0.77 & 0.44 \\
$\quad$ (dorsal landmark) & $(0.61-0.85)$ & $(0.26-0.59)$ \\
Radial shortening & 0.22 & 0.27 \\
$\quad$ (volar landmark) & $(0.02-0.42)$ & $(0.07-0.45)$ \\
\hline
\end{tabular}

\section{RESULTS}

Subject characteristics are presented in Table 1. Inter-rater reliability for radiographical measures was higher for prereduction films than for postreduction films (Table 2). Radial shortening, radial inclination and dorsal angulation were all substantially reliable (kappa greater than 0.60 ) (20) when measured on prereduction films. Radial inclination was substantially reliable on postreduction films. The use of a volar landmark of the radial surface resulted in poor reliability.

Exact agreement (unweighted diagonal agreement) occurred in $39 \%$ to $65 \%$ of cases where fractures were classified (Table 3). A high preponderance of intra-articular fractures occurred in the sample, leading to imbalance between category utilization. Of the classification systems, only the Older system approached excellent reliability (kappa $=0.73$ ) or achieved the minimum acceptable standard accepted by The Journal of Orthopaedic Trauma (kappa greater than 0.55). Although the Older classification system had the highest reliability, it was designed for use with extra-articular fractures and has not previously been used to describe intra-articular fractures. In review of the disagreements on fracture classification, it was observed that disagreements tended to occur when the decision was 'borderline'; for example, when the joint was minimally involved, there was a small ulnar head fracture or a minimal extension into ulnar wrist, etc.

\section{DISCUSSION}

The present study showed that the reliability of routine radiographical classification of DRF among hand surgery fellows using a variety of systems was below accepted standards. The level of reliability observed reflected that which is expected under current clinical situations. Reliability may be enhanced with further training and practice, suggesting that more of this should be incorporated into the routine training of residents and fellows. The lack of substantial agreement on radiographical classifications found in this study is in agreement with the majority of studies in this area, including studies conducted with raters having different experience 
levels, and using different scales and different joints (2-5,7-12).

The only classification system to show excellent reliability was the Older system. The Older classification system was designed for use with extra-articular fractures but can be applied to any distal radius fracture because it addresses displacement (shortening) and comminution. A previous study of 185 extra-articular fractures classified by the Older system showed 'high' intrarater (kappa $=0.75)$ and inter-rater $($ kappa $=0.69)$ agreement $(34)-$ similar to that found in the present study (kappa $=0.73$ ). Currently, the Older system is not used for intra-articular fractures. Additional evidence on its reliability and validity may be required to convince clinicians to change their current practice patterns. The Older system addresses radial length, dorsal angulation and comminution, and the present study showed that dorsal angle and radial shortening measurements have excellent reliability on prereduction films (ICCs greater than 0.77 ). Therefore, consideration must be given to the relative benefits and disadvantages of an ordinal scale incorporating these measures compared with the use of the measures themselves.

The Universal system proposed by Rayhack (35) addressed articular involvement and stability. It has been suggested that its simplicity and relation to treatment indications are appealing (36). In the current study, observed agreement was highest for this system (65\%), although the chance corrected agreement was only a kappa of 0.36 . Fellows provided favourable feedback on the use of this system and liked both its structure and its relation to clinical practice. For this reason, efforts to enhance its reliability may be warranted.

The Mayo classification system was designed specifically for intra-articular fractures and addresses displacement and extent of joint involvement. The McMurtry system for intraarticular fractures classifies fractures according to the number of parts. Neither of these systems demonstrated acceptable inter-rater reliability for the two fellows used in the present study. Because neither rater used any of these classification systems routinely, it is entirely possible that further training or experience would result in higher reliability for any of the classification systems evaluated in the present study. However, our chart audits indicate that it is not common clinical practice for physicians to record either a classification or a direct measurement of fracture severity. If these measures are 'eyeballed' in clinical practice and measured for research purposes, then rater reliability will remain problematic.

The present study showed that direct measurement exhibited much higher inter-rater reliability than did classifications. Perhaps, rather than concentrating on new and improved classifications, efforts should be directed toward incorporating these direct measures into routine clinical practice and defining levels at which specific interventions are required. Although postreduction measures were less reliable, this may partially reflect the increase in homogeneity of the study sample because patients were restored to a more uniform anatomical position after fracture reduction. Conversely, casts, healed fracture lines, etc, may obscure visuali-
TABLE 3

Inter-rater reliability of fracture classifications (95\% confidence interval $[\mathrm{CI}]$ )

\begin{tabular}{|c|c|c|c|}
\hline Classification & $\begin{array}{c}\text { Observed } \\
\text { diagonal } \\
\text { agreement } \\
\text { (unweighted) }\end{array}$ & $\begin{array}{c}\text { Kappa } \\
(95 \% \mathrm{CI}) \\
\end{array}$ & $\begin{array}{c}\text { Intraclass correlation } \\
\text { coefficient }(95 \% \mathrm{CI})\end{array}$ \\
\hline Older & 56 & $\begin{array}{c}0.73 \\
(0.62-0.84)\end{array}$ & $\begin{array}{c}0.71 \\
(0.59-0.80)\end{array}$ \\
\hline Frykman & 47 & $\begin{array}{c}0.35 \\
(0.16-0.54)\end{array}$ & $\begin{array}{c}0.44 \\
(0.24-0.60)\end{array}$ \\
\hline Mayo & 49 & $\begin{array}{c}0.33 \\
(0.11-0.57)\end{array}$ & $\begin{array}{c}0.34 \\
(0.15-0.52)\end{array}$ \\
\hline Universal & 65 & $\begin{array}{c}0.36 \\
(0.15-0.57)\end{array}$ & $\begin{array}{c}0.41 \\
(0.21-0.58)\end{array}$ \\
\hline McMurtry & 39 & $\begin{array}{c}0.41 \\
(0.21-0.61)\end{array}$ & $\begin{array}{c}0.34 \\
(0.15-0.50)\end{array}$ \\
\hline \multicolumn{4}{|l|}{$\mathrm{AO}$} \\
\hline Type & 67 & $\begin{array}{c}0.38 \\
(0.15-0.61)\end{array}$ & $\begin{array}{c}0.35 \\
(0.17-0.52)\end{array}$ \\
\hline Group & 44 & $\begin{array}{c}0.33 \\
(0.10-0.56)\end{array}$ & $\begin{array}{c}0.30 \\
(0.12-0.47)\end{array}$ \\
\hline Subgroup & & & $\begin{array}{c}0.33 \\
(0.17-0.51)\end{array}$ \\
\hline
\end{tabular}

zation of fractures in the postreduction situation and result in an increase in error when reading postreduction films.

The most commonly reported radiographical measures are dorsal angulation and shortening. A study by van der Linden and Ericson (23) analyzed a variety of radiographical measures and related covariation among dorsal angle, dorsal shift, radial angle, shortening and radial shift in 202 displaced fractures. They found that the two measurements of dorsal displacement were highly correlated (ie, dorsal angulation and dorsal shift). They recommended the use of dorsal angle because it is easier to measure. Others have also suggested that up to $50 \%$ of measured shortening is related to rotation and changed position of the radial styloid (17).

Radial shortening can be measured through a variety of methods. Warwick et al (22) showed that measurement from the articular surfaces of the radius and ulna was more related to outcome than other methods of measuring radial shortening. However, the articular surface of the radius can be problematic because it presents a palmar and dorsal edge and is affected by ulnar and palmar tilt (17). Some authors have suggested alternative methods of measuring radial shortening to address this problem (17). The present study showed that the use of a volar articular surface as a landmark resulted in inferior reliability.

\section{CONCLUSIONS}

Under the conditions whereby fellows do not routinely use a single classification system, nor routinely record direct measures of bony displacement from the radiograph, poor inter-rater reliability exists for all but the Older classification 
system, whereas direct measurement of bony displacement has excellent inter-rater reliability in prereduction films. Postreduction measurements are less reliable than prereduction measurements. More comprehensive training and evaluation of skill may need to be incorporated into training programs to enhance radiographical classification reliability between clinicians. However, given the reliability of direct radiographical measures, efforts may be better directed into incorporating these measures into clinical decision-making and research communications.

\begin{tabular}{|c|c|}
\hline \multicolumn{2}{|c|}{$\begin{array}{l}\text { A } \\
\text { Universal classification system for distal radius } \\
\text { fractures (reference } 35 \text { ) }\end{array}$} \\
\hline Classification of fracture & Treatment preference \\
\hline Nonarticular & Cast immobilization \\
\hline Nonarticular, displaced & $\begin{array}{l}\text { Cast immobilization } \\
\text { Percutaneous pins } \\
\text { Open reduction or external fixation }\end{array}$ \\
\hline Articular, nondisplaced & $\begin{array}{l}\text { Cast immobilization } \\
\text { Percutaneous pins }\end{array}$ \\
\hline \multicolumn{2}{|l|}{ Articular, displaced } \\
\hline Reducible, stable & $\begin{array}{l}\text { Closed reduction } \\
\text { Percutaneous pins (K-wires) }\end{array}$ \\
\hline Reducible, unstable & $\begin{array}{l}\text { Closed reduction } \\
\text { External fixation (with or without } \\
\quad \text { percutaneous pins) }\end{array}$ \\
\hline Irreducible & $\begin{array}{l}\text { Open reduction or external fixation } \\
\text { with percutaneous pins }\end{array}$ \\
\hline Complex & $\begin{array}{l}\text { Open reduction or external fixation } \\
\text { Plate fixation with bone graft (with } \\
\quad \text { or without percutaneous pins) }\end{array}$ \\
\hline
\end{tabular}

B

Older classification system for distal radius fractures (reference 29)

Type I: Nondisplaced

loss of some volar angulation and up to 5 of dorsal angulation no significant shortening $2 \mathrm{~mm}$ or more above the distal radius

\section{Type II: Displaced}

loss of volar angulation or dorsal displacement of distal fragment

shortening usually not below the distal ulna, but occasionally up to $3 \mathrm{~mm}$ below it minimal comminution of the distal radius

\section{Type III: Displaced with comminution of the dorsal ra- dius \\ comminution of the distal radius shortening usually below the distal ulna comminution of the distal fragment usually not marked and often characterized by large pieces}

\section{APPENDIX 1}

\section{Fracture classification systems}

\section{Type IV: Displaced with severe comminution of the radial head \\ marked comminution of the dorsal radius comminution of the distal radial fragment shattered shortening usually 2 to $8 \mathrm{~mm}$ below the distal ulna poor volar cortex in some cases}

C

Frykman classification system for distal radius fractures (reference 30)

Type 1: extra-articular

Type 2: type 1 with fracture of the distal ulna

Type 3: radiocarpal joint involved

Type 4: type 3 with fracture of the distal ulna

Type 5: distal radioulnar joint involved

Type 6: type 5 with fracture of the distal ulna

Type 7: radiocarpal and radioulnar joints both involved

Type 8: type 7 with fracture of the distal ulna

D

Mayo classification system for distal radius fractures (intra-articular fractures) (reference 26)

Type I

Extra-articular radiocarpal joint; intra-articular in radioulnar joint

Type II

A displaced intra-articular fracture of the radioscaphoid joint involving a significant portion of the articular surface of the distal radius (more than a radial styloid fracture). Associated dorsal angulation and shortening necessary components of the fracture.

\section{Type III}

A displaced intra-articular fracture of the radiolunate joint that often presents as a 'die-punch' fracture of the lunate fossa. A fracture component displaced into the distal radioulnar joint is common.

\section{Type IV}

A displaced intra-articular fracture involving both the radioscaphoid joint surfaces and usually involving the sigmoid fossa of the radioulnar joint. This fracture is usually comminuted. 


\section{APPENDIX 1 (continued) \\ E \\ McMurtry classification system for distal radius fractures (reference 28) \\ Two-part}

The opposite portion of the radioulnar joint remains intact

\section{Three-part}

The lunate and scaphoid facets of the distal radius separate from each other and from the proximal portion of the radius

\section{Four-part}

Similar to the three-part except that the lunate facet is further divided into volar and dorsal fragments

\section{Five-part}

Includes a wide variety of comminuted fragments

\section{F}

AO classification system for distal radius fractures (reference 24)

Types (A, B and C) are divided into groups (1,2 and 3 ) and each group is further subdivided into subgroups as listed below.

\section{Type A - Extra-articular}

Extra-articular fractures involving neither the radiocarpal nor the radioulnar joint

$\mathbf{A}_{\mathbf{1}}$ : Isolated fractures of the ulnar metaphysis

ulnar styloid

simple metaphyseal fracture

comminuted metaphyseal fracture

$\mathbf{A}_{2}$ : Extra-articular fracture of the radius, simple but impacted. (These are subdivided into subgroups depending on the orientation of the fracture line and the direction of the displacement of the distal fragment)

nondisplaced

dorsal displacement (Colles-Pouteau)

volar displacement (Smith-Goyrand)
$\mathbf{A}_{3}$ : Extra-articular fracture of the radius, multifragment with varying degrees of metaphyseal impaction

impacted (shortening)

with metaphyseal comminution

with metaphyseal-diaphyseal comminution

\section{Type B: Simple articular}

Fracture affects a portion of the articular surface, but the continuity of the metaphysis and epiphysis is intact

$\mathbf{B}_{1}$ : Cuneiform articular fracture of the distal radius radial styloid comminuted radial styloid ulnar 'wedge' fracture

$\mathbf{B}_{2}$ : Dorsal margin fracture (Barton's fracture) simple associated with radial styloid fragment associated with radiocarpal dorsal dislocation

$\mathbf{B}_{3}$ : Volar margin fracture (reversed Barton's, Letenneur) volar radial fragment (sigmoid notch intact) volar fragment (affecting sigmoid notch) comminuted volar fragment

\section{Type C: Complex articular}

A fracture that affects both the joint surface and the metaphyseal area

$\mathbf{C}_{1}$ : Articular fracture of the radius simple articular component (two fragments and no metaphyseal comminution)

Colles fracture affecting the radioulnar joint

Colles fracture with dorsoulnar articular fragment

$\mathrm{T}$-fracture in the sagittal plane

$\mathbf{C}_{2}$ : Articular fracture of the radius with simple articular component and metaphyseal comminution

Colles fracture affecting the radioulnar joint

T-sagittal fracture

T-frontal fracture

$\mathbf{C}_{3}$ : Comminuted articular fracture of the radius without metaphyseal comminution (four-part fracture) with metaphyseal comminution with metaphyseal-diaphyseal comminution
ACKNOWLEDGEMENT: The authors thank Dr Marilena Marignani for her assistance with reading radiographs.

\section{REFERENCES}

1. Sanders RW. The problem with apples and oranges. J Orthop Trauma 1997;11:466.

2. Nielsen JO, Dons-Jensen H, Sorenson HT. Lauge-Hansen classification of malleorlar fractures: An assessment of the reproducibility in 118 cases. Acta Orthop Scand 1990;61:385-7.

3. Rasmussen S, Madsen PV, Bennicke K. Observer variation in the Lauge-Hansen classification of ankle fractures: precision improved by instruction. Acta Orthop Scand 1993;64:693-4.

4. Thomsen NO, Overgaard S, Olsen LH, Hansen H, Nielsen ST. Observer variation in the radiographic classification of ankle fractures. J Bone Joint Surg [Br] 1991;73B:676-8.
5. Bright AS, Torpey B, Magid D, Codd T, McFarland EG. Reliability of radiographic evaluation for acromial morphology. Skeletal Radiol 1997;26:718-21.

6. McCaskie AW, Brown AR, Thompson JR, Gregg PJ. Radiological evaluation of the interfaces after cemented total hip replacement. Interobserver and intraobserver agreement. J Bone Joint Surg [Br] 1996;78:191-4

7. Kreder HJ, Hanel DP, McKee M, Jupiter JB, McGillivary G, Swiontkowski MF. Consistency of AO fracture classification for the distal radius. J Bone Joint Surg [Br] 1996;78B:726-31.

8. Horn BD, Rettig ME. Interobserver reliability in the Gustilo and Andersen classification of open fractures. J Orthop Trauma 1993; 7:357-60

9. Sidor ML, Zuckerman JD, Lyon T, Koval K, Cuomo F, Schoenberg N. The Neer classification system for proximal humeral fractures. An assessment of interobserver reliability and intraobserver reproducibility. J Bone Joint Surg [Am] 1993;75:1745-50. 
10. Siebenrock KA, Gerber C. The reproducibility of classification of fractures of the proximal end of the humerus. J Bone Joint Surg [Am] 1993;75:1751-5.

11. Brien H, Noftall F, MacMaster S, Cummings T, Landells C, Rockwood P. Neer's classification system: a critical appraisal. J Trauma 1995;38:257-60.

12. Johnstone DJ, Radford WJP, Parnell EJ. Interobserver variation using the AO/ASIF classification of long bones fractures. Injury 1993;24:163-5.

13. Thomsen NOB, Jensen CM, Sicovgaard N, et al. Observer variation in the radiographic classification of fractures of the neck of the femur using Garden's system. Int J Orthop 1996;20:326-9.

14. Swiontkowski MF, Sands AK, Agel J, Diab M, Schwappach JR, Kreder HJ. Interobserver variation in the AO/OTA fracture classification system for pilon fractures: is there a problem? J Orthop Trauma 1997;11:467-70

15. Martin JS, Marsh JL, Bonar SK, Decoster TA, Found EM, Brandser EA. Assessment of the AO/ASIF fracture classification for the distal tibia. J Orthop Trauma 1997;11:477-83.

16. Andersen DJ, Blair WI, Steyers CM, Adams BD, El-Khour AY, Brandser ED. Classification of distal radius fractures: an analysis of interobserver reliability and intraobserver reproducibility. J Hand Surg [Am] 1996;21:574-82.

17. Bilic R, Ruzic L, Zdravkovic V, Boljevic Z, Kovanjanic J. Reliability of different methods of determination of radial shortening. J Hand Surg [Br] 1995;20B:97-101.

18. Kreder HJ, Hanel DP, McKee M, Jupiter J, McGillivary G, Swiontkowski MF. X-ray film measurements for healed distal radius fractures. J Hand Surg [Am] 1996;21:31-9.

19. Fleiss JL. The Design and Analysis of Clinical Experiments. Toronto: John Wiley and Sons, 1986.

20. Landis JR, Koch GG. The measurement of observer agreement for categorical data. Biometrics 1977;33:159-74.

21. Burstein AH. Fracture classification systems: do they work and are they useful? J Bone Joint Surg [Am] 1993;75:1743-4.

22. Warwick D, Prothero D, Field J, Bannister G. Radiological measurement of radial shortening in Colles' Fracture. J Hand Surg [Br] 1993;18:50-2.
23. van der Linden W, Ericson R. Colles fracture: how should its displacement be measured and how should it be immobilized? J Bone Joint Surg [Am] 1981;63:1285-8.

24. Muller ME, Nazarian S, Koch P, Schatzker J. The Comprehensive Classification of Long Bones. New York: Springer-Verlag, 1990:54-63.

25. Cooney WP. Fractures of the distal radius. A modern treatment-based classification. Orthop Clin North Am 1993;24:211-6.

26. Raskin KB, Melone CPJ. Unstable articular fractures of the distal radius. Comparative techniques of ligamentotaxis. Orthop Clin North Am 1993;24:275-86.

27. Graff S, Jupiter J. Fracture of the distal radius: classification of treatment and indications for external fixation. Injury 1994;25(Suppl 4):D14-25.

28. McMurtry RY, Jupiter JB. Fractures of the distal radius. In: Browner BD, Jupiter JB, Levine AM, Trafton PG, eds. Skeletal Trauma. Philadelphia: WB Saunders Co, 1996:1063-93.

29. Older TM, Stabler EV, Cassebaum WH. Colles fracture: evaluation and selection of therapy. J Trauma 1965;5:469-76.

30. Frykman G. Fracture of the distal radius including sequelae - shoulder hand finger syndrome, disturbance in the radioulnar joint and impairment of nerve function. A clinical and experimental study. Acta Orthop Scand 1967;108:1-155.

31. Shrout PE, Fleiss JL. Intraclass correlations: Uses in assessing rater reliability. Psychol Bull 1979;86:420-8.

32. Maclure M, Willet WC. Misinterpretation and misuse of the kappa statistic. J Epidemiol 1987;126:161-8.

33. Cohen J. Weighted kappa: nominal scale agreement with provision for scaled disagreement or partial credit. Psychol Bull 1968;70:213-20.

34. Andersen GR, Rasmussen JB, Dahl B, Solgaard S. Older's classification of Colles' fractures. Good intraobserver and interobserver reproducibility in 185 cases. Acta Orthop Scand 1991;62:463-4

35. Rayhack J. Symposium on distal radius fractures. Contemp Orthop 1990;21:75.

36. Jupiter JB, Fernandez DL. Comparative classification for fractures of the distal end of the radius. J Hand Surg [Am] 1997;22:563-71. 


\section{ERRATUM}

In the March/April 2001 issue of the Journal, there was a misprint. The name $\mathrm{Dr}$ Kevin Hydebrand was spelled incorrectly on the cover, and on pages 43 and 51 . It should have been spelled as Dr Kevin Hildebrand. Our kindest apologies are extended to Dr Hildebrand. 